\title{
CAPÍTULO 8 \\ AVALIAÇÃO DE IMPACTO AMBIENTAL E A GESTÃo DO MEIO AMBIENTE.
}

\author{
Milla Cristina Santos Da Cruz ${ }^{1 ; 2}$.E-mail:millasantos@gmail.com \\ Rafael de Lima Souza²; Fabiane Frances Araújo Frances²; Raissa Jennifer da \\ Silva de $\mathrm{Sá}^{2}$ \\ 1;2 - Autora para correspondência \\ 2 - Universidade do Estado do Pará - Engenharia Ambietnal_2015_Campus VI - \\ Paragominas - PA. \\ DOI:10.4322/978-85-455202-0-7-08
}

\begin{abstract}
RESUMO
Com o crescimento populacional, ocorreu o aumento da degradação dos recursos naturais, na qual foi necessário a criação de novas tecnologias e leis, para tentar amenizar os impactos ambientais negativos causados pelas ações do homem. $\mathrm{O}$ objetivo da pesquisa foi correlacionar os Estudos Prévios da Avalição de Impactos Ambientais - EPIA com a gestão ambiental na mitigação dos impactos causados por ações antrópicas. Quanto ao método de pesquisa, possui um caráter dedutivo, com procedimento exploratório e abordagem qualitativa. A avaliação de impactos ambientais e a gestão ambiental é um processo contínuo. Diante disto, que o desenvolvimento da sociedade de forma descontrolada, gera grandes impactos ambientais e, para mitiga-los, o poder público, a Avaliação de Impactos Ambientais - AIA, e EPIA são utilizadas em conjunto para amenizar e/ou prevenir os danos ambientais.
\end{abstract}

PALAVRAS-CHAVE: Consequências. Desenvolvimento econômico. Recursos naturais.

\begin{abstract}
With population growth, there has been an increase in the degradation of natural resources, which required the creation of new technologies and laws to try to mitigate the negative environmental impacts caused by human actions. The objective of the research was to correlate the Environmental Impact Assessment - EPIA with environmental management in mitigating the impacts caused by anthropogenic actions. As for the research method, it has a deductive character, with exploratory procedure and qualitative approach. The assessment of environmental impacts and environmental management is an ongoing process. In view of this, that the development of society in an uncontrolled way, generates great environmental impacts and, to mitigate them, public power, EIA and EPIA are used together to reduce and / or prevent environmental damage.
\end{abstract}


KEY WORDS: Consequences. Economic development. Natural resources.

\section{INTRODUÇÃO}

A humanidade, a partir do crescimento da degradação dos recursos naturais, tornou-se preocupada com a proteção ambiental o que tornou necessária a criação de instrumentos para defender o meio ambiente. Por isso, a implantação de qualquer atividade ou obra efetiva ou potencialmente causadora de impacto ambiental significativo, deve submeter-se a uma análise e controle prévios dos possíveis impactos a serem gerados (CECCONELLO, 2009).

Por isso, o estudo prévio deve avaliar as alternativas de concepção, tecnológicas, de localização e de técnicas construtivas previstas, justificando a alternativa adotada, sob os pontos de vista técnico, ambiental e econômico, deve também avaliar a compatibilidade com a legislação ambiental federal, estadual e municipal aplicável ao empreendimento, sem deixar de explicitar as medidas mitigadoras de impactos ambientais (BRASIL, 2013).

Todavia, a avaliação de impacto ambiental - AIA, surgiu como resposta jurídica para o desenvolvimento econômico dos estados alinhados a uma proteçao ambiental de seus recursos naturais, sendo hoje, tida como um dos principais instrumentos do direito ambiental, tanto na esfera interna quanto internacional (MILARÉ, 2011).

Decerto, o processo de AIA visa a identificação e a previsão dos impactos sobre o meio ambiente, decorrentes das atividades antrópicas, e sistematicamente propor medidas de redução e eliminação dos impactos negativos (MORGAN, 2012).

Por outro lado, a AIA é vista como uma ferramenta de planejamento, sendo utilizada como instrumento de prevenção do dano ambiental e como um procedimento definido no ambito das politicas publicas, e tem objetivo de garantir que essas ações tenham os fatores ambientais incluido e equacionados ainda nos estagios iniciais do processo decisório, com o mesmo peso que as questões socias e economicas (SIRVINSKAS, 2012).

Então, a avaliação de impacto ambiental passou a ter significativa importância nacional e internacional ao passar das décadas, por conta do progressivo desenvolvimento economico-social e da necessidade de vincula-ló a uma poteção ambiental dos recursos necessarios a esse desenvolvimento (PASSOS, 2009).

Assim também, o processo de gestão ambiental surge da necessidade do ser humano organizar melhor as diversas formas de relacionar-se com o meio ambiente, de maneira que tem como objetivo o controle apropriado do meio ambiente físico, para propiciar o uso com o mínimo desgaste, de modo a manter as comunidades biológicas, para o benefício continuado do ser humano (JABBOUR et al., 2009).

Por certo, a gestão ambiental é uma abordagem sistêmica em que a preocupação ambiental está em todos os aspectos dos negócios das organizações. A implementação desse sistema de gestão, normalmente, é um processo voluntário. Ao optar pela sua implantação, as companhias não estão visando apenas os benefícios financeiros. 
Estão também, estimando os riscos de não gerenciar adequadamente seus aspectos ambientais, sendo abordada entao como maneira preventiva (OSKISSON,2009).

Logo, em relação a gestão ambiental, sabe-se que houve uma série de ramos ambientais devido à preocupação com o meio ambiente, e entre eles destacam-se a Gestão Ambiental e o Direito Ambiental. Na qual, o Direito Ambiental utiliza como principal instrumento, o Estudo Prévio de Impacto Ambiental - EPIA, e seu e seu respectivo relatório de Impacto Ambiental - RIMA (DINIZ, 2011).

Diante disso, é notório que o caráter preventivo deve prevalecer sobre o corretivo, mas este problema ainda não foi bem assimilado, o que justifica essa pesquisa, cuja relevância é incrementada pela necessidade de que se estude com mais profundidade a correlação entre a avaliação de impacto ambiental e a gestão ambiental, como ferramenta para evitar ou mitigar consequências ao meio ambiente, no qual se tornou objetivo dessa pesquisa.

\section{A REVOLUÇÃO INDUSTRIAL E A LEGISLAÇÃO AMBIENTAL}

A Revolução Industrial, marco histórico no qual deu origem ao capitalismo, impôs novo ritmo às relações sociais e profissionais, e exerceu influência na relação entre o homem e a natureza. Por conta disso, as constantes modificações do habitat foram uma consequência inevitável do aumento populacional, uma vez que os anseios por bens de consumo são diretamente proporcionais a esse crescente (POZZOBON, 2011).

Logo, iniciou-se o conflito entre crescimento econômico e preservação ambiental. A primeira indaga a inviabilidade de parar o desenvolvimento econômico, enquanto que a segunda, correlaciona-se com a dignidade da pessoa, na medida em que uma vida digna pressupõe uma vida saudável, que só pode advir de um meio ambiente equilibrado (SIMÕES; PAGANELLI, 2013).

Além disso, em diversos países do mundo, como Alemanha, Finlândia e Holanda, a questão ambiental assume uma posição central no que diz a respeito sobre a preservação. A política ambiental brasileira vem sendo caracterizada principalmente pela regulação através de normas com a grande finalidade de controlar o acesso e uso dos recursos naturais buscando preservá-los para as presentes e futuras gerações (FARIAS; COUTINHO, 2010).

Por consequência, começaram a se desenvolver métodos com o objetivo de sistematizar as análises realizadas com técnicas de outras áreas do conhecimento. Embora a maioria dos trabalhos de análise de impacto ambiental tenha começado nos Estados Unidos, o interesse do assunto expandiu-se tanto nos países industrializados quanto nos países em desenvolvimento (OLIVEIRA, MOURA, 2009).

Com isso, no Brasil foi criada a Lei Federal n. 6.938 em 31 de agosto de 1981 que dispõe da Politica Nacional do Meio Ambiente- PNMA, é um dispositivo constitucional regulador do meio ambiente, que determina o não uso indiscriminadode determinado bem, quando sua utilização colocar em risco o equilibrio ambiental, de maneira que a 
ação governamental objetiva a manutenção do equilibrio ecologico (CARIBÉ; DIAS 2011).

Certamente, a finalidade da PNMA é a preservação, melhoria e recuperação da qualidade ambiental. Para isso, a lei considera o meio ambiente como um patrimônio público a ser assegurado e protegido para o uso coletivo. Apontando o princípio da racionalização do uso do solo, o planejamento e fiscalização dos recursos ambientais, a proteção dos ecossistemas e o controle do zoneamentodas atividades poliuidoras (CARDOSO, 2012).

De acordo com isso, o Conselho Nacional do Meio Ambiente-CONAMA estabeleceu, por meio da Resolução 001:1986 as definições das responsabilidades, os critérios básicos e as diretrizes gerais para uso e implementação de Avaliação de Impacto Ambiental como um dos instrumentos da Política Nacional do Meio Ambiente, possuindo grande importância para toda a sociedade, pois evita a realização de obras e projetos propensos a causar impacto ambiental (MILARÉ, 2013).

Ademais, o CONAMA edita resoluções de modo a conferir aos vários tipos de empreendimentos, os critérios e estudos necessários à análise dos respectivos impactos e, com base em critérios técnicos, estabelece as espécies de estudos de impacto ambiental a serem exigidos para determinada atividade (FERRAZ; FELIPE, 2012).

Acerca da gestão ambiental e do Estudos de impacto ambiental, os mesmos apresentam afinidades entre si, de maneira que é perceptível entre eles especialmente na questão da fundamentação que se foca principalmente na prevenção, precaução e no desenvolvimento sustentável, como também no que tange as fases/requisitos de ambos e seus objetivos (SANCHES, 2013).

\section{METODOLOGIA}

O método utilizado nesta pesquisa foi o dedutivo, pois parte de princípios reconhecidos como verdadeiros e indiscutíveis, a exemplo da avaliação de impactos ambientais que é utilizada como instrumento da política nacional do meio ambiente, e a relação do caráter preventivo da AIA e a gestão ambiental. Possibilitando chegar a conclusões que no Brasil possui leis e gestões preventivas para o equilíbrio do meio ambiente (GIL, 2008).

O procedimento aplicado foi o exploratório, visto que propõe maior familiaridade com o problema (fenômeno a ser investigado), com vista a torná-lo mais explícito ou construir hipóteses, e abrangência qualitativa (GERHARDT; SILVEIRA, 2009), pois, não se preocupa com representatividade numérica, mas, sim, com o aprofundamento da compreensão de um grupo social, nessa pesquisa, a comunidade que utiliza os recursos naturais, e de uma organização, aqui representada pelo CONAMA.

Quanto ao procedimento, ou seja, o modo pelo qual foi feita a coleta dos dados, é bibliográfico, visto que, é desenvolvida a partir de material já elaborado, constituído principalmente de livros e artigos científico (PRODANOV; FREITAS, 2013) e foi 
baseada em bibliografias publicadas entre 2009 a 2018, sobre relação da AIA com a gestão ambiental, ambas de caráter preventivo.

\section{DISCUSSÕES}

Segundo Barbieri (2011), diz que as primeiras manifestações de gestão ambiental foram estimuladas pelo esgotamento de recursos, como a escassez de madeira para a construção de moradias, fortificações, móveis, instrumentos e combustível, cuja exploração havia se tornada intensa. A gestão do processo tem ligação direta com a ação humana, pois tem a pretensão de conduzir as atitudes sociais no espaço natural, através de regramentos no componente (ar, água, solo, etc.) estimulando um repensar sobre a conduta perante os recursos naturais limitados.

Diante disso, as propostas de gestão ambiental incluem no mínimo três dimensões: a) dimensão espacial, que diz respeito à área na qual se espera que as ações de gestão tenham eficácia (global, local, empresarial, etc.); b) a dimensão temática, que demarca as questões ambientais às quais as ações se destinam (águas, solo, fauna e flora, etc.); e, c) dimensão institucional, relativa aos agentes que tomaram as iniciativas de gestão (empresa, sociedade civil, etc.).

De acordo com César e Carneiro (2016), verifica-se que a legislação brasileira está alinhada às diretrizes internacionais, como do Programa das Nações Unidas para o Meio Ambiente - PNUMA, criada em 1972, visto que a legislação ambiental brasileira possui uma sistemática do processo de licenciamento que facilita em teoria o monitoramento pelos órgãos ambientais responsáveis por estudos ambientais nos processos de gestão ambiental.

Segundo Braga (2009), devido as pressões negativas sobre os recursos naturais e uso de tecnologias de baixa eficiência ecológica que o processo de desenvolvimento economico propriciou aos recursos naturais, a AIA é um instrumento legal que busca mitigar as acões antropicas das atividades exploradas pelo desenvolvimento econômico, mediante a essa pespectiva, a avaliação de impactos ambientais torna-se indispensavel, pois tem o proposito de alinhar os interesses do crescimento economicos com a proteçao ambiental.

De acordo com a pesquisa de Rendin e Silveira (2012), a avaliação dos impactos ambientais de determinando empreendimento não se encerra com o estudo ambiental exigido no início do licenciamento. A avaliação de impactos ambientais é um processo contínuo, tanto que determinadas atividades se submetem ao chamado monitoramento ambiental, caso, por exemplo, de atividades emissoras de efluentes. A própria validade temporária de uma licença ambiental, a qual tem que ser constantemente renovada, é prova de que a avaliação de impactos ambientais é um instrumento dinâmico, constante. 


\section{CONSIDERAÇÕES FINAIS}

Com o desenvolvimento da sociedade de forma descontrolada, o poder público surge com o objetivo de amenizar os impactos ambientais negativos causado pelo homem. No qual, a interação entre a gestão ambiental e o estudo prévio de impacto ambiental, vem como instrumento capaz de realizar avaliações ambientais de prazo curto, médio e longo. De maneira, que os empreendimentos auxiliam quanto a não geração de impactos que elevam o passivo ambiental das empresas.

Portanto, a AIA resulta em uma ferramenta significativa da gestão ambiental, cuja a sua aplicação é essencial para diminuir os impactos ambientais negativos, servindo como ferramenta de proteção e prevenção ao dano ambiental, porem fica perceptivel que essa é apenas mais uma dos encargos da gestão ambiental pelo qual seus conceitos e etapas acabam se interagindo e tendo finalidades entre si, resultando em consequências positivas, cuja sua aplicação se torna mais facil e eficaz.

\section{REFERÊNCIAS}

BARBIERI, J. C. Gestão Ambiental Empresarial: Conceitos, modelos e instrumentos. 3ed. São Paulo: Saraiva, 2011.

BRAGA, R. Dinâmica regional, industrialização e sustentabilidade ambiental no Estado de São Paulo: Uma visão a partir da Região Administrativa de Campinas SP. In: XII Encontro da Associação Nacional de Pós-Graduação e Pesquisa em Planejamento Urbano e Regional. Florianópolis, SC.2009.

BRASIL. Resolução Cema n. 086 de 2 de abril de 2013. Estabelece diretrizes e critérios orientadores para o licenciamento e outorga, projeto, implantação, operação e encerramento de aterros sanitários.

CARDOSO, E. R. S. Um instrumento Econômico de Política Ambiental: Usos e Limitações. Anais da sociedade Brasileira de Economia. Administração e Sociologia rural, 2012.

CARIBÉ, R. C. V.; DIAS, J. Qualidade ambiental: reflexões sobre o conceito. Revista Eletrônica IBAMA, Brasília, n. 1, 2011. Disponível em: < w.Ibama.gov.br ascom@Ibama.gov.br. Acesso em: 18 mar. 2018.

CECCONELLO, V. M. O estudo de impacto ambiental. Revista Direito \& Justiça. Porto Alegre, v. 35. n. 2, p. 137-147, jul. /dez. 2009.

CÉSAR, P. S. M.; CARNEIRO, R. A. Gestão Ambiental em Minas Gerais: uma análise do sistema de gestão ambiental e do rompimento da barragem de rejeitos em mariana. Revista Livre de Sustentabilidade e Empreendedorismo, v. 2, n. 2, p. 192217, 2016. 
DINIZ, R. H. C. O estudo prévio de impacto ambiental e a gestão ambiental: semelhanças e interações. Revista Âmbito Jurídico, Rio Grande, XIV, n. 94, nov. 2011. Disponível em: <http://www.ambitojuridico.com.br/site/index.php?n_link=revista_artigos_leitura \&artigo_id=10674>. Acesso em 15 mar. 2018.

FARIAS, T.; COUTINHO, F. S. N. Direito Ambiental: o meio ambiente e os desafios da contemporaneidade. Belo Horizonte: Fórum, 2010.

FERRAZ, F. B.; FELIPE, T. J. S. análise comparativa entre avaliação e estudo de impacto ambiental. Revista do Programa de Pós-Graduação em Direito da UFC. Fortaleza, v.32.2, jul. /dez. 2012.

GERHARDT, T. E; SILVEIRA D. T. Métodos de pesquisa. Porto Alegre: Editora da UFRGS, 2009.

GIL, A. C. Métodos e técnicas de pesquisa social. 6 ed. São Paulo, Atlas, 2008.

JABBOUR, C. J. C.; SANTOS, F. C. A.; NAGANO, M. S. Análise do relacionamento entre estágios evolutivos da gestão ambiental e dimensões de recursos humanos: estado da arte e Survey em empresas brasileiras. Revistas de Administração, São Paulo, v. 44, n. 4, p.342-364, dez. 2009. Trimestral.

MILARÉ, E. Direito do Ambiente: a Gestão ambiental em foco. 7.ed. São Paulo, Revista dos Tribunais, 2011.

MORGAN, R. K. Environmental impact assessment: the state of the art. Environment Impact Review. v. 30, n.1, p 5-14. 2012.

OLIVEIRA, F. C.; MOURA, H. J. T. uso das metodologias de avaliação de impacto ambiental em estudos realizados no Ceará. Revista imprensa, Belo Horizonte, v.10, n.4, p.79-98, out. /dez. 2009.

OSKISSON, R. E. et al. Estratégia competitiva. São Paulo: Cengage Learning, 2009.

PASSOS, P. N. C. A conferência de Estocolmo como ponto de partida para a proteção internacional do meio ambiente. Revista de Direitos Fundamentais e Democracia, Curitiba, v.6, p.1-25, 2009.

POZZOBON, M. P. Responsabilidades no licenciamento ambiental e no estudo de impacto ambiental, 2011. Disponível em https://www.agrolink.com.br/georreferenciamento/artigo/responsabilidades-nolicenciamento-ambiental-e-no-estudo-de-impacto-ambiental_136551.html > Acesso em: 15 mar. 2018.

PRODANOV, C. C; FREITAS, E. C. Metodologia do trabalho científico: métodos e técnicas da pesquisa e do trabalho acadêmico. 2 ed. Novo Hamburgo: Feevale. 2013. 
REDIN, E.; SILVEIRA, P. R. C. Política ambiental brasileira: limitações e desafios. Caderno de Pesquisa Interdisciplinar em Ciências Humanas. Florianópolis, v.13, n.103, p.163-188, ago. /dez 2012.

SÁNCHEZ, L. E. Avaliação de impacto ambiental: conceitos e métodos. 2 ed. São Paulo: Oficina de Textos, 2013.

SIMÕES, A. G.; PAGANELLI, C. J. M. A natureza difusa do direito fundamental a um meio ambiente ecologicamente equilibrado. Revista Âmbito Jurídico, Rio Grande, XVI, n. 111, abr. 2013. Disponível em: < http://ambitojuridico.com.br/site/?n_link=revista_artigos_leitura\&artigo_id=12718\&rev ista_caderno=5>. Acesso em 15 mar 2018.

SIRVINSKAS, L. P. Manual de direito ambiental. São Paulo: Saraiva, 2012. 